Catchline (head of first page only) International Journal of Qualitative Studies in Education Vol. X, No. X, Month 200X, pp. 000-000

Running heads (verso) D. Nixon and N. Givens

(recto) An epitaph to section 28?

\title{
An epitaph to section 28? Telling tales out of school about changes and challenges to discourses of sexuality ${ }^{1}$
}

David Nixon $^{\mathrm{a}}$ and Nick Givens ${ }^{\mathrm{b}^{*}}$

${ }^{\mathrm{a}}$ University of Exeter, $U K ;{ }^{\mathrm{b}}$ University of Exeter, $U K$ 


\title{
An epitaph to section 28? Telling tales out of school about changes and challenges to discourses of sexuality
}

\begin{abstract}
This article seeks to develop an understanding of the professional and personal lives of LGBT teachers in relation to the discriminatory statute Section 28 which prohibited "promotion" of "the acceptability of homosexuality as a pretended family relationship" by Local Education Authorities in the UK (except Northern Ireland). Interviews with a small sample of serving teachers are analysed using a feminist poststructuralist methodology to discover whether the removal of this legislation marks a shift in theorization, policy or practice. Findings are arranged to focus on the workings of official policy, on informal or unofficial classroom and staffroom practices, and on relations with a local community. Analysis and discussion reveal a complex matrix of constituents (space, relationships and other variables) only some of which respond to the (perhaps) superficial stimulus of legislative change. Such change goes only a small way to challenge a deeply embedded discourse of inequality, which may respond only to a more profound epistemological transformation.
\end{abstract}


An epitaph to section 28? Telling tales out of school about changes and challenges to discourses of sexuality

Biographical notes

Nick Givens is a Lecturer in Education at the University of Exeter. His research interests are in equalities within education, with a particular interest in sexualities, and ethnicity \& "race", in the pre-service training and ongoing professional development of teachers.

Correspondence to Nick Givens, School of Education and Lifelong Learning, University of Exeter, Heavitree Road,Exeter,EX1 2LU, UK. email: N.Givens@ex.ac.uk

Dr David Nixon is an Honorary Research Fellow in the University of Exeter, and lectures there part time on the Childhood and Youth Studies degree. He works full time as a parish priest. His research interests include aspects of social exclusion/inclusion with a particular focus on issues of sexuality in education and the church.

Correspondence address: SELL, St. Luke's Campus, Exeter EX1 2LU, UK

email:rev.dave@virgin.net 
An epitaph to section 28? Telling tales out of school about changes and challenges to discourses of sexuality

\section{Introduction}

As part of the New Right agenda in the 1980s, Section 28 sought to impose on local authorities (and therefore on schools) a particular view of sexualities, aimed at repressing and restricting the emerging public debate. In the context of schools it was hoped that "family values", including heterosexual marriage, would be buttressed by outlawing the "promotion" of "the acceptability of homosexuality as a pretended family relationship". The relevant wording is as follows (Department of Education and Science, 1988):

(1) A local authority shall not (a) intentionally promote homosexuality or publish material with the intention of promoting homosexuality; (b) promote the teaching in any maintained school of the acceptability of homosexuality as a pretended family relationship. (2) Nothing in subsection (1) above shall be taken to prohibit the doing of anything for the purpose of treating or preventing the spread of disease.

While the legislation was muddled on two counts - not applying directly to schools but to local authorities, and not preventing work around sexual health - it nevertheless had the desired effect of encouraging teachers to self-censor in what was in any case regarded as a problematic subject area (Harris, 1990; Smith, 1990; Epstein, 1994). The strength of opposition to removing this statute, driven principally by an alliance of conservative and religious thinking, demonstrates to some extent the symbolic effect associated with it (Burridge 2004), namely that it "signals official and legal disapproval of homosexuality, which both reflects and produces inequalities" (Epstein 2000). 
Section 28 had always been regarded by the lesbian, gay, bisexual, trans-sexual (LGBT) community as a totemic piece of discriminatory legislation. Its removal from statute in 2003 (2000 in Scotland) was part of a wider UK Government agenda to extend civil rights amongst LGBT people, including an equalization of the age of consent, adoption by same-sex couples and civil partnerships. Its demise seems to have been mourned by none except for right-wing religious groups, so perhaps it would be wiser to promote no epitaph at all. However, just as this legislation was designed to reinforce a certain politically-inspired view of sexualities in schools, so it is right to ask whether its removal marks a shift in theorization, policy or practice. Beyond the theoretical interest this might hold, the lives of teachers and pupils are intimately touched by such legislation. Additionally, it is well-understood that the reach of hegemonic masculinity, thoroughly entwined in the maintenance of heteronormative pressures, affects all pupils and teachers, so that discussion here has implications for the whole school community (e.g. Capper, 1999; Nixon, 2003).

Our earlier study (Nixon \& Givens, 2004) looked at the lives of six LGBT trainee teachers at one Higher Education Institution (HEI). Interviews were conducted in 2000 while a Labour Government made a first, unsuccessful attempt to repeal Section 28. This study focused on students' experiences of their pre-service training, of placements in schools, and on their lives in the city and at home. Results were used to produce profiles of the participants which were then examined both vertically (providing a snapshot of each individual) and horizontally (offering comparison between individuals with regard to emerging themes). Complementary and competing aspects of the discourses around sexuality were found to operate at three levels: that of the campus, within schooling, and finally across society as a whole. We therefore conceptualized these student teachers as inhabiting simultaneously these three overlapping worlds - facing a minefield of negotiation in order to confirm their professional socialization as teachers. The findings were 
mapped onto three themes: localized discrimination and prejudice, the management of personal and public identity, and the operation of hegemonic masculinity.

Despite the generally liberal self-perception of this HEI, considerable homophobia and heterosexism were revealed. This ranged from curricular silence to outright verbal and physical hostility from other students, from heterosexist assumptions and stereotyping to fear of discovery. This was broadly consistent with the literature available about schools and colleges (Lilley, 1985; Squirrell, 1989; Rhoads, 1994; Sparkes, 1994; Squires \& Sparkes, 1996; Clarke, 1996; Ferfolja, 1998, Williamson, 2001; Clarke, 2002; Epstein, O’Flynn \& Telford 2003). However, far from being perceived in any sense as "victims", these six young men and women showed considerable courage and resistance, sometimes through the use of humor, as they sought sustainable identities. Additionally, they revealed their diversity, both in their experiences of being an LGBT student teacher, as well as in their interpretation of those experiences.

The identity issues engaged and revealed by this research prompt us as researchers to clarify and evaluate our own positioning in respect of both the participants and the findings (Sparkes, 1994). As white, middle-aged, middle-class, able-bodied in appearance, male academics, we are aware that what we write about carries with it the privileges associated with these membership categories; and further, that intentionally or not, these privileges are also implicated in the processes which lead to the discrimination we describe. While our differential membership of the category of sexuality (one gay, the other straight) gives us both exploratory tensions and insights, our overall weighting still lies on the side of privilege (Allen 2006:168). We are therefore loaded with both responsibilities and cautions around our actions. We are also conscious of the problematic nature of LGBT as a category: its use risks collusion with fixed and polarizing identities, which have been destabilized by Queer Theory; its avoidance fails those teachers and pupils for whom the category 
is made concrete through the enactment of homophobia and heterosexism against them. We note similarities with Gaine's (2005) position concerning "race", namely that "race" ought not to matter, but currently does, and in order to make it matter less, we need to pay attention to it.

With regard to the politics of education, we share the view that in pursuit of social justice, homophobia and heterosexism in educational settings need to be challenged, and that our privileged positions confer on us the responsibility for finding and carrying out our contributions to that work. Our data suggests that heteronormativity (with heterosexism and homophobia in attendance) will prevail in educational settings unless such institutions actively and explicitly promote sexualities equality. Both authors are active in teaching about gender, sexuality and equalities in Initial Teacher Education (ITE) and undergraduate education programmes. While we welcome legislation and official guidance that seeks to extend civil rights and to undermine discourses that pathologize, oppress or victimize, we also recognize that legal and official strategies alone are only a start. We see "breaking the silence" about homophobia as an essential ingredient of pursuing social justice in relation to sexualities equality.

Mindful of Griffiths' (1998) call for "greater reflexivity and clarity” and the problematically different dimensions attributable to the concept of "giving voice", our first attack on this silence, ("Miss, you're so gay”, Nixon \& Givens, 2004) was an attempt to represent the voices of those who told us they were often marginalized by their courses and in their social lives both by being "written out" of both course material and social interaction, while at the same finding themselves only too visible and "audible" when more overt prejudice and discrimination were actualized. It is only within the last decade or so that such voices have been heard within the academy touching upon the lives of LGBT trainee teachers and LGBT teachers. Our study was used subsequently at one HEI to promote greater awareness in the research and teaching community; and 
amongst trainee teachers, to create space where it was possible to speak about these matters. At the same institution, an inter-agency forum was established to focus on different aspects of student LGBT life. For pupils, however, we are only too aware that greater visibility on its own may risk an increase in homophobic discrimination (Rogers, 1994; Epstein et al, 2003). Indeed, when Ellis \& High (2004) revisited Trench \& Warren's (1984) study Something to tell you, they found that far from an improved situation for LGBT pupils, their data suggested a $10 \%$ increase in physical assault, a $29 \%$ increase in verbal abuse and a $27 \%$ increase in the isolation of young victims of homophobic bullying in schools.

Our previous research admitted the uncomfortable and ambiguous position occupied by researchers in terms of empowerment and voice, as well as indicating where such reflexive learning was possible from the research subjects themselves; the times Dewar indicates "that I need to be silent, listen, and take responsibility for learning" (1993: 222). We were also guided by Lincoln's notion of authenticity that: "the reader should come away from such texts with heightened sensitivities to the lives being depicted" (1993: 37), and Richardson's suggestion that "we can choose to write so that the voice of those we write about is respected, strong and true" (1990: 38). For this present research, we have also made more explicit our own privileged memberships, and their potential to influence our work.

\section{Analytical framework}

Both pieces of research are underpinned by poststructuralist analysis of identity and power, and by a feminist impetus to advocate and introduce more equitable thinking and practice based around the notion of gender. While these two bodies of thought have sometimes been juxtaposed in opposition, their more recent 
combinations described as "invigorating and fruitful" (St. Pierre, 2000: 477), provide the researcher with precise theoretical tools to analyze situated sexualities, and to recommend appropriate responses. Francis' (2001: 76) distinction between postmodernism and poststructuralism is instructive:

Where postmodern writers often argue that identity has become fragmented by consumerism, globalisation etc. a poststructuralist position maintains that the self was never unitary but has always been positioned in discourse.

Such positioning results in subjects who are "volatile, contradictory and changing, rather than rational, unified and static beings" (Robinson, 2005: 23). Individuals both position themselves within multiple discourses around gender and sexuality, asserting and resisting these discourses for their own ends, and at the same time are susceptible to the placement others give to them. Such an interplay of forces, a dance of potential identities, removes for ever a simple binary division between heterosexuality and homosexuality (Mac an Ghaill, 1994; Jagose, 1996; Atkinson 2002a). Queer theory, which grew out of and arguably away from the stable of lesbian and gay studies, wishing itself to remain amorphously postmodern in definition (Walters, 2005) drew on poststructuralist tools to examine sexualities more intensely, and thereby found itself ready to destabilize all identity categories. Jagose (1996: 132) summarizes thus: "Queer is not outside the magnetic field of identity. Like some postmodern architecture, it turns identity inside out, and displays its supports exoskeletally." Some of those supports prove to be chimerical, and queer is not reluctant to display the absence of empire's clothes or its own conceptual short-comings, as Sedgwick does in her essay challenging certain antihomophobic assumptions, and recommending a putative set of new axioms (Sedgwick, 2005). The replacement of fixed definitions of sexuality (and thereby moving to a plural sexualities) by one of shifting and fluid perspectives, extends additionally to recognizing that the discourses around race, ethnicity and social class also impact variably and differentially (Ellis \& Forrest, 2000). In this respect, the idea of 
"constellations" of subjectivities, which both create and constrain the individual, is a helpful one (Youdell, 2005).

Foucault's (1970) suggestion that we excavate an archaeology of power (what he came later to call genealogy) to reveal the buried codes of our culture, and to expose the constructed nature of the classifications we have taken to be innate is applied to the specific realm of sexuality in a later work. His intention "to define the regime of power-knowledge-pleasure that sustains the discourse on human sexuality in our part of the world" (1998: 11) reveals how discourses both transmit and produce power, as well as challenging it providing spaces for resistance. More domestically, Walkerdine (1989: 2) describes this process as "like unpicking knitting”. Such deconstructive work is far from simply destructive, for in discovering how practice, thinking, behavior and so on have been inscribed, there is the opportunity to demonstrate how this may be reinscribed differently and more equitably (St. Pierre, 2000). This marks an epistemological break with the social liberation movements of the 1960's (civil rights, gay and lesbian, and so on) which challenged the disparities of subordination from within the humanist paradigm; by contrast, Foucault and the penumbra of post- movements with which he was associated, wished to discomfort these familiar patterns of thinking, without establishing a clear-cut alternative. So "power relations" or "relations of power" are better descriptors of what Foucault believes is occurring; and his intention is to discover not passively what is taking place, but what those relations of power are creating (Foucault, 1997). The easy interpretation of power as exclusively hierarchical is discredited by the concept of resistance. Resistance is not only an effect of power relations themselves, in fact engendered by them, but also, even in the most extreme of circumstances, remains within the grasp of the poststructuralist subject; as St. Pierre (2000: 504) suggests: "agency seems to lie in the subject's ability to decode and recode its identity within discursive formations and cultural practices." 
In the domain of education, Gee (1996: viii) develops these views, defining discourses as "ways of behaving, interacting, valuing, thinking, believing, speaking, and very often reading and writing that are accepted as instantiations of particular roles by specific groups of people.” They are means of being "people like us", each containing a tacit theory of what counts as normal. His example of the pedagogy of a US Law School (a parallel instance of Higher Education-based professional socialization in which some students must negotiate competing discourses) is instructive, given Nikki's earlier comment in reference to gay sexuality "you start asking yourself whether you should be a teacher". Gee demonstrates the reification of one discourse: the process by which such thinking, behavior and so on is inscribed and prescribed. This is a conflict of identity, since who I am in one discourse may mean that I am expected to act against who I am in another. Discourses which lend themselves to the acquisition of social goods (money, power, status) and a significant place in a hierarchical structure, Gee (1996) calls dominant discourses. Similar work in the area of "race" suggests the existence of "identity traps" where black boys are trapped in a "double-bind", forced to choose between success in local (racialized) street culture and success in academic achievement (Youdell, 2003).

Poststructuralist methodologies offer very real advantages in terms of analyzing the operation of discourses and power, and the multiple identities thereby created and produced. They also offer heuristic space to reimagine new discourses which open up previously closed binary divides. Feminists have operated this in two ways: firstly in exploring the way patriarchy creates and regulates gendered subjects; and secondly in seeing that 'woman' is not a totalizing term beyond issues of race, ethnicity, social class and sexuality (e.g. Lorde, 1984; Walkerdine 1989; Spivak, 1993; Butler, 1997; Hawley, 2001; Reay 2001; Atkinson 2002a).

Poststructural feminists also remind us that the quest for social justice is in itself overladen with assumptions (Sedgwick, 2005), but that the "space of freedom available to us is not at all insignificant and we have the ability to analyze, contest and change practices that are being used to construct ourselves in the world, as well 
as the practices we ourselves are using in this work of praxis" (St Pierre 2000: 493). Beyond this, however, Francis (2001: 73) recognizes that postmodernism and poststructuralism tend to deny the possibility of speaking for anyone except the self, leading to a "fragmented emancipation"; on the other hand, a learning and listening process allows us a degree of agency.

We can choose to talk to, form relationships with, and read about the experiences of people with different material characteristics. In this way we are able to learn about and to imagine what it is like to experience life from their perspective.

She contends that there is also some coherence to our personalities, which are formed by a mixture of consistency and inconsistency over time, space and experience, both within ourselves and in relation to others. This allows the existence of feminism as an "interpretive community", where members share enough common ground to continue to work for social justice. This article claims engagement with such a community, offering one interpretation of the data put before it, seeking opportunities for "destabilising and critiquing the status quo through an examination of [the] subtle exercise of power" (Atkinson 2002a: 83) and for the production of "knowledge from which to act" (Lather 1991:39).

Viewed through the lens of this analytical framework, the legislative force of Section 28 sought to curtail a rebalancing of different elements within the debate around sexualities in public education (perhaps to prevent real debate altogether); equally, then, the repeal of Section 28 was intended to re-open debate, and allow policy and practice in schools to reflect aspirations towards "a supportive and tolerant society" (House of Commons Library 2000:22)

\section{Methods}


Having developed a post-structural approach through our earlier work we wished to progress our study longitudinally. Of the six students originally interviewed, three were interviewed again in 2004, having completed between two and four years in the classroom. These three interviews were carried out by telephone, and analyzed by both researchers, working with tapes and transcripts. By means of semi-structured interviews, we wished to form a picture of how discourses around sexualities were played out in the microcosm of particular schools and in the lives of individual teachers; to look through the eyes, and experience the personal and professional worlds of LGBT teachers, already confident about their sexualities; to prompt comment about conflicting discourses, identity management and the hidden levers of power and responsibility.

Longitudinal study (scarce in this field) offered continuity, and opportunities to make comparisons over time and trace shifts in position. It also provided some defense against artificial separation of participants' professional and personal transitions over the timespan of becoming qualified then established as teachers. Interviews were chosen to afford opportunities to follow up issues, and explore nuances and complexities as they unfolded: with such a small sample, the depth of discussion enabled by interviews was also an advantage. Participants' familiarity with the researchers cut both ways, carrying vestiges of both trust and power relations of prior relationships: interviews opened with discussion of participants' current teaching posts and responsibilities, to foreground their status as established teachers. Anonymity was provided through the use of pseudonyms, continued from our first study, and by auditing outputs to ensure that identities could not be deduced. Because of the inherent sensitivity of the interviews, participants were directed to sources of professional and personal LGBT support they could access should they so wish. Interview structure and method were designed to prioritize 'lack of harm or detriment to participants'. For example, conscious of our relative privilege we deemed it inappropriate to discuss sexual practices (despite their centrality to Queer Theory) unless participants raised this topic: they did not, so we did not pursue this theme. 
Our interview questions focused on: What was it like to be an LGBT teacher in the classroom and staffroom? Had their pre-service training and NQT year prepared them for this professional life? What impact did this professional life have on their personal lives, and what did they see when they looked back at their "histories"? Was the existence and subsequent repeal of Section 28 significant - how did they see things changing? And finally, what were their thoughts for the future, and would they recommend the profession to other LGBT people?

The three teachers who agreed to be interviewed again were:

- Nikki, teaching for four years in a primary school in a London borough, with a position of responsibility and (at the time of the interview) about to take on an additional position

- Andrew, teaching secondary science for two years in a comprehensive school in South East England, (at the time of the interview) about to take on a position of responsibility

- Laura, teaching secondary PE for four years in a comprehensive school in South West England, with a position of responsibility

(All three still work in the schools where they first started after qualifying.)

\section{Analysis and discussion}

If Section 28 was intended to inscribe a particular thinking about sexualities in schools, indeed to police the transmission of a traditional understanding of sexualities within society more generally, then its repeal suggests a shift in this outlook, and permission in schools to imagine and create a more equitable position. We intend here, following Walkerdine (1989), to "unpick the knitting" of this potential shift, looking 
firstly at evidence from these three interviews to support the contention that policy, attitudes and practice in primary and secondary schooling are changing, but such change is constrained. In a second section we discuss the nature of these constraints and examine the informal networks of influence, the kind of "power relations" of which Foucault (1997) speaks, that operate like a strong current beneath official policy in the particular sites of staffroom, classroom and playground. These form networks or matrices of power built around complex constituents or variables (Youdell, 2005), which may prove less susceptible to policy-driven changes. A final section looks more closely at such variables as gender, "race", religion, ethnicity and space within schools and the geographical location of schools.

\section{From policy to practice: the limits of legislation}

We've got an awful lot around the school which is to do with equal opportunities and in every classroom there is a Rights and Responsibilities in Equal Opportunities poster, which, when it says that you are treating everybody with a respect and all of this, it does say, when it says gender and race and all of this, it does say sexual orientation as well, so that is in the classroom, and I know that I use that quite a lot in dealing with situations that arise: "Would you mind going and reading that poster to me please?" and things like that. ... there was a woman who used to do the equal opportunities thing - she was from drama, so she was very dramatic and everything, but she used to do this assembly once a year to the whole school, and everyone can tell you about her school assembly. Now I never saw it, but it was to do with these squirrels and all the children would be able to tell you about the squirrel assembly. It was to do with - one of the squirrels was gay in the end, but she'd led them on this massive long story about these squirrels and the punch-line to it was, the squirrel was gay and you loved this squirrel now. So it is dealt with within the school. [Andrew]

The Borough that I'm in, the Borough as a whole, has a really big inclusion policy which is, it goes from including all children to including all adults, really so far as sexuality goes, then there is a big thing about it not being an issue at all. [Nikki] 
It's not a case of "oh, you're gay and that's really nice", it's not patronizing, because I know that would be really easy to do that; it's just a case of I can just as easily say to somebody I have got a girlfriend as someone else can say that they've got a boyfriend, people just don't flinch about it. [Nikki]

[Sexuality / sexual orientation] features in bullying in the sense that if there is homophobic abuse directed at a member of staff or directed at a child, then it's recorded as with racial abuse and racial bullying ... [Laura]

Together with two government publications, Bullying- don't suffer in silence (2002) and Stand up for us: challenging homophobia in schools (2004), there is evidence from these interview quotations (above) that the official discourse around homosexuality (attached to a discourse of equal opportunities, diversity and in the case of Stand up for us also to school attendance and attainment) has shifted at least contemporaneously if not causally with the repeal of Section 28. The kind of deconstructive work which poststructuralist analysis suggests is necessary to uncover the covert mechanisms of power (Davies, 1997), gives way here to the beginnings of reconstructive work which envisages a more equitable inscription of sexualities equalities (St. Pierre, 2000). The silence of self-censorship, enforced narrowly by the law and interpreted widely by the schools' community, has been replaced by a higher profile naming, recording and even normalizing - Andrew talks of the "squirrel assembly" at second-hand since it has passed into school mythology. This is further supported in this series of interviews by Laura's description of events in her NQT year. She describes an outdoor PE lesson interrupted by aggressive boys on bicycles, who

stood around me and were shouting things, and then one of the girls had actually brought a mobile phone out to the lesson and had it in her pocket; so I took it off her and the girl said, "Can I have my phone back?" I said, "Ill give it you in the changing rooms," and the lads started shouting "Oh yeah, that's what we've heard that happens - you do that to the girls in the changing rooms." 
On another occasion she overhears two girls planning to entrap her in a compromising situation, but is able to thwart this. When Laura decided to report these incidents, she received managerial support. Indeed, she believes that her actions "maybe woke the school up" to something it ought to have been addressing; nevertheless, "I did let a number of incidents happen before I decided that actually I had to do something."

Even while Laura herself regarded the outcome of this event as positive, there are the beginnings of slippage from the more emancipatory stance encouraged by official documents and policy statements. Responsibility had been effectively passed back to her to "wake the school up" in response to an incident which itself reveals the limits of formal ambition around sexualities in schools. The clash of discourses is revealed sharply in these exchanges: unofficial homophobia against official equalities. It is Laura who is given support from the school structures, which itself indicates a transformation from the days of Jane Brown and Romeo and Juliet (Epstein, 1996), but there is no indication that the pupils in question have had their behavior challenged.

A similar process is uncovered in our first study during pre-service training. While the university provider and the official student body promoted their own equal opportunities policies, these hardly impacted on the deeply inscribed discourses which problematize teaching for gay and lesbian people. As Nikki came to terms with her sexual identity, she implicitly vocalized exactly the self-censorship which Section 28 had insidiously imposed. Having started the course, she wondered whether she could be gay and be a teacher, and no one seemed willing to help her:

That's something that I had a problem with to start with because you start asking yourself whether you should be a teacher. I've never asked anybody if I should or not. But it's never covered and I've never known whether I should or not.

What Nikki highlights may be read as the conflict between two discourses, the discourse of being homosexual and the discourse of being a teacher. The conflict of identity described by Gee (1996) in the Law School is 
exemplified here: Nikki's identity in her learnt discourse (teacher) may mean that she is expected to act against her identity in her primary discourse (LGBT). It is by pursuing the professionalism of teaching that she gains access to the rewards associated with dominant discourses - the social goods of power, status and money, and a significant place in the social hierarchy, but this gain is made potentially at the expense of another significant identity factor. This is further complicated by the fact that as a white teacher she is already the recipient of the goods attached to the primary discourse around color and "race" (Ellis and Forrest, 2000). Four years later, in a different political, legislative climate, when Nikki is asked what she would say to a young LGBT person thinking of teaching and what she would say to a course provider, she replies:

I'd say don't let the fact that you're gay impact upon your choices really. ... So as far as someone running a course goes, I think they just need to make people aware that it's all right. Because especially if you're starting a course as an 18 year old you think you know quite a lot but actually really you don't. And things like that, that people might think are really obvious. If you're just becoming aware - because when I started at X, as far as I was concerned, I wasn't gay. So, having to deal with that in my first year and then go through "should I be teaching?" and "should I tell anybody if I'm going to be a teacher about it?” was quite difficult I think, and I think people need to just - I suppose it's a hard thing to just turn around and say “it's all right to be gay and be a teacher", but it just would have been nice I suppose for somebody to acknowledge that that's all right.

This repetition of concern, and the need for explicit assurance, echoing almost exactly what was said in 2000 , and her additional hope that any conflation between pedophilia and homosexuality is robustly challenged ("if you're gay then you must be a bit warped so you shouldn't be working with children."), reinforce the assertion that changes at the level of legislation and policy have had limited success in effecting changes at a more profound level to underlying discourses around sexualities. Nikki engages here in her own piece of queer theorizing, as she uncovers the means by which the discourse of being a teacher constructs itself so that it positions individuals differentially in respect of their sexualities (Robinson, 2005). The mechanisms of 
control range from unspoken, negative assumptions to quasi-criminal accusations, attempting to affix boundaries to the profession which Queer so playfully disrupts (Jagose, 1996).

The limited scope of any transformation towards equality is further revealed by working in the opposite direction, from the discourse of being an LGBT person towards the discourse of being a teacher. Rofes (2000: 459) writes about attempting to negotiate the boundaries of acceptable behavior between the worlds of some contemporary gay, male culture ("cyber sex, drag, sex in parks or participation in leather sub-cultures") and that of the educator. He emphasizes what has been lost:

we've made compromises and sacrifices that have gone unspoken and unacknowledged. We've gained limited entry into the classroom by denying authentic differences between many gay men's relationships to gender roles, sexual cultures and kinship arrangements compared with those of the heteronormative hegemony.

In other words, there is an absence from school policy and curriculum of positive affirmations of what it means to be a lesbian or gay young person, or to be parented by same-sex adults. The silence surrounding the challenge to stereotypical gender roles emphasized in LGBT households replicates the silence used historically to disempower, disavow, disqualify and disappear the homosexual person in society. This curricular silence may be what effectively pushes back the responsibility for action to the minority, and simultaneously undermines any challenge to heteronormativity by minoritizing the issue.

The "wake-up call" promoted by Laura does not simply extend to mitigating the more obvious examples of homophobia, but opens up a space for asking where responsibility is situated for education around sexualities. The inherent dangers of an individualized approach are illustrated in this research by Andrew: 
I think a lot of it is down to what you do yourself as a teacher, because within what I do in Science, it's very different the sort of things that we cover, as to what a historian, who's dealing with historical perspectives and looking at the slave trade and different things like that, they would be raising different issues in their classrooms, whereas I wouldn't be raising those sort of issues. I would be raising different sorts of things, different sorts of ethical issues within my subject.

Ellis \& High (2004) suggest that sex education may not be the best site for teaching about sexuality, given the "epistemological ambivalence" which surrounds this aspect of the curriculum. But in advocating education about sexuality throughout the curriculum as an aspect of culture and identity, they are also only too aware of the pitfalls of this approach. The power of individual teachers to frame sexuality education around a personal and indisputable moral framework, that "could have led to disciplinary action in the case of gender or "race"” (p. 222), points to the need for in-service and pre-service training around relating personal and professional values to issues of sexuality and sexual identity. These developments have to be seen as the responsibility of the whole school, in planning and implementation, or it will inevitably return to be considered an interest for a minority of teachers and pupils and best engaged by them (Williamson, 2001). More positively, the recruitment of an LGBT newly qualified teacher (NQT), gives schools not only the possibility of embracing diversity, but also the opportunity "to capitalize on creative potential and professional commitment of graduate entrants to the education service" (Tickle, 2000: 2).

Via interviews with three teachers, this section has described and analyzed the extent to which the formal structures of schooling have responded to an altered legislative framework for the discussion of sexualities. The constraints on change have come at three points: at the intersection of formal and informal discourses, when responsibility needs to be taken to challenge inappropriate action and behavior, and when positive affirmation of alternative sexualities is required. Given the history of legislation around (male) homosexuality (Weeks, 1996), the positive move towards sexualities equalities signaled by this change should not be 
underestimated, but neither should the strength and flexibility of the discourse which essentializes and minoritizes be discounted. Although the UK government's recent stance on tackling homophobia - regarding pupils through anti bullying advice to schools (Department for Education and Skills (DFES) 2002), followed by more specific guidance (DFES / Department of Health (2004), and regarding teachers through The Employment Equality (Sexual Orientation) Regulations (Department of Trade and Industry 2003) - reflects the same seriousness of intent as the repeal of Section 28 , there is still more focus on symptoms than on causes. The extent of constraints described above might be mitigated if the model applied to the Race Relations Amendment Act (2000) and the Disability Discrimination Act (2005) were followed in terms of sexualities. These Acts advocate a "positive duty" to promote good and harmonious relationships, and to take steps to prevent illegal discrimination. Behind and beneath legislation lies the significant and all-embracing informal discourse around sexualities and schooling, whose strands of complexity reinforce deeply inscribed hegemonies. The next task is to excavate this archeology of power (Foucault, 1970), to disentangle these matrices of influence within informal sites of discourse of sexualities in schools - staffroom, classroom and playground (Mac an Ghaill, 1994).

Where the real power lies

I know the kids use the terms "gay", and "poof' and all of that almost without even thinking about them, but I know that there are a few kids who have had an awful lot of grief in the classroom and in my classroom as well. And you do as much as you can to try and stop it but you can't deal with everything, and you sort of pass various things on but then you think at the end of the day, well I can't devote all my time to this, and one child in particular who's in year 11, I know, he used to quite happily wind the rest of the class up about his big question mark over his sexuality, he would come in one day showing pictures of his girlfriend, and then he'd come in the next day with a video with Brad Pitt on saying how gorgeous Brad Pitt was. And no wonder the whole class didn't really understand the guy, when he's leading them this big old song and dance about himself. So I think he was very confused himself, but also the rest of the class didn't know how to relate to him, and I didn't know how to relate to the kid because he'd come 
and you'd stick up for him one lesson and then he'd come and do something else, and I'd be like, why did I even make an issue out of it? [Andrew]

We had our end of year drinks and I got really drunk and just decided that enough was enough, and so sort of went from table to table and said, "You know I'm gay, don't you?" And half of the table would go "Yes" and the other half would go "No, but that's fine". Yes, and then, well it was quite embarrassing! [Nikki]

He was a very large lad and he got very interested in PE at one stage and he used to come to me and say "Miss I've started going to the gym" and things "cos all the boys at the moment are really thin and nobody will look at me"; he'd talk about his weekends very, very openly and what he was doing and things like that and I just allowed him to talk really and let him tell me about things. All his group of mates, all the girls who used to hang around with him used to talk about it all, the fact that they'd been out with him and things like this and I just allowed them to talk. They would then say 'would you ever go out Miss clubbing or anything in that environment' and I would just say well I don't see any reason why I wouldn't no, without sort of obviously telling them about myself. But I think he was very astute in it and he was very observant and picked up a lot of things just about me in the typical PE teacher, short-hair category and I think he thought that I probably was gay because he would say “oh when I leave Miss we'll meet for a drink in town" and things like that and when he left in $6^{\text {th }}$ form, and he was very - almost as if saying "I know you are". It was quite strange really. ... he is actually a character and almost like a kind of a friend that I think I will miss now that he's left because I guess in a way he was a kind of role model for me to be more confident about myself in school through seeing his experiences at school and how he dealt with it and how he didn't hide the fact, he didn't hide it at all. He didn't hide it with the group of hard boys as it were, he didn't change and he was just him. [Laura]

These three interview extracts demonstrate the shifting sands of sexualities discourse within informal sites of discussion, touching upon the complex, fluid and multi-dimensional approaches needed for their negotiation. Andrew recognizes the prevalence of homophobic abuse in playground and classroom (Lilley, 1985; Epstein, 1998) with language almost voided of any real meaning (except for those "selected"), replicating a comment from a previous interview: (Nixon and Givens, 2004: 225 ) 'He's gay, she's gay, this work's gay, this game's 
gay, everything." (Atkinson 2002b; Wallace, 2005). He also recognizes his role as a teacher in challenging such iterations, but implicitly wonders perhaps where the boundaries to this challenge lie. His irritation with the young man's uncertainty about his sexuality suggests a binary view between hetero- and homosexuality which Andrew is keen to clarify. He is less keen to extend this need for clarity to others when it comes to explaining his own position to his pupils, saying that "it's not an appropriate question to be asking a teacher." While the traditional teacher-pupil power dynamic here may be maintained, it risks leaving unsupported an individual pupil as he lives through the fluidity around sexuality identity.

The contested issue of "coming out" (Khayatt, 1999; Talburt, 2000; DFES, 2004) is evidenced in this research by all three interviewees, who are conscious of the need for identity management, and as trainee teachers had all hoped to teach in schools where they could be open about their sexuality (Nixon and Givens, 2004). The reality of their present experiences implies that such clear-cut hopes may be rarely met, given the complexity of relations between different stakeholders in the educational process: between members of staff, between teachers and pupils, between teachers and parents, and between pupils themselves.

In terms of the staff room, Nikki demonstrates the subtle (and less subtle) processes of an average sized London primary school. Her unscripted experience at a social gathering is part of a longer process she has consciously engaged and reflected upon, even to the extent of some forethought given to the relaxed opportunities at the end of term party itself. She has spoken to individuals slowly over the course of her first year in the school, judging their potential reactions, based partly on age (the younger were deemed to be more accepting) and partly on culture. She was concerned that two female Muslim teachers knew her first as a person in her own right, and then as a gay person ("there were a couple of Muslim teachers I didn't want to tell for a little while, because I wanted them to know who I was before, before they made any judgment of 
me"). The third variable here is that of family connection. One teacher has known Nikki and her family for many years, and there is hesitation on Nikki's part about her reactions; at the time of the interview, she had not told her grandmother. A final variable returns to the more formal school transactions concerning the Head: "My headteacher, I really just needed to clarify that she knew ...". Another facet of complexity is instilled when the abstract "coming out" is made real by the introduction of a live same-sex partner. Nikki manages this in the way that Gemma is introduced - "my friend", "my friend who I share a house with", "my girlfriend" - depending on the kind of event. These past strategies have led her to a present position in which: "I suppose everybody knows, all of my staffroom now, so ... I suppose if anything when conversations get going in the staffroom I probably get grouped with the boys ... but not in a way I wouldn't encourage, I suppose." This is further evidence of an easy conflation of gender and sexuality, which is not resisted, by the same individual who sharply resists others conflations, echoing Sedgwick's phrase that definitions here are “irredeemably slippery” (Sedgwick, 2005). Robinson’s (2005) concept of volatile, changeable subjects seeking to negotiate sexual positionings is represented in the density of the process Nikki engages.

On first sight, Andrew may seem unsympathetic in terms of managing his sexual identity; however, his sophisticated and almost playful delight in keeping his pupils guessing about his sexual identity ("they were going absolutely nuts because they wanted to know and I just said to them 'I'm not going to tell you'.') reveals an awareness of complex, differential power positions, which he is consciously operating with some skill and humor, exemplifying even here that there is space for agency and resistance (Foucault, 1997). That such space is also limited given the informal power of the pupil culture in relation to all teachers (Lahelma, Palmu \& Gordon 2000) and to LGBT teachers in particular is also evidenced: 
because the kids pick up on the tiniest little insecurities and the they play on them. I mean, as soon as you open your door they're watching what shoes you're wearing, what socks, what trousers, what belt, what tie, what shirt, and all of your mannerisms, your actions, your voice, your hair, and if there's something that they can pick up on they're like vultures.

In waiting until the end of his NQT year to tell a handful of staff colleagues about his sexual orientation, he acknowledges that he did not wish to be positioned as "the new gay one", recognizing the potential to be trapped in an identity which as a teacher may not be advantageous to him, or which may overshadow other identity factors (Youdell, 2003).

Laura's description of her experience with a male PE pupil as "strange" implies at least a partial realization of reversed roles and hierarchies. That he has almost become a role model for her, suggesting ways of being in the school which matches much more with her own hopes of openness than she has so far achieved, is unsurprising given the configurations of influence (Sparkes, 1994; Griffin, 2002). The contrasts are illustrative: he is a large male, sufficiently interested in PE and his physique, and sufficiently attentive to his own physical attraction to other men, that he uses the gym as both a site of dominance within the school ("he didn't hide it with a group of hard boys"), and a site of seduction (probably), outside ("I've started going to the gym cos all the boys at the moment are really thin and nobody will look at me"); she is "the typical PE teacher, short-hair category", "obviously gay", and as she has already experienced, vulnerable to accusations of impropriety as she supervises changing-rooms. The expected structuring of teacher-pupil relations within a school cannot match the already inscribed discourses around both gender and sexualities, and so gives way to a reconfiguration which (implicitly) both parties are aware of and surprised by, but as individuals are powerless to challenge. Perhaps resistance is offered by the post-school invitation of "a drink in town", which will equalize their relationship in social terms, which Laura does not directly reject. The "gain" for the pupil here is further pastoral support, but almost all the risk is born by Laura. Two discourses here work against her: 
that which privileges men over women (e.g. Walkerdine, 1989); and a homophobic discourse which easily mixes "lesbian PE teacher" with inappropriate behavior towards pupils.

A comparative study illustrating the way such forces play out in the life of a similar individual is described by Sparkes' (1994) account of the professional and private struggles of "Jessica". She is forced to adopt "identity management strategies" in response to the heterosexual hegemony which polices not only her every move but her very essence, forcing her into a public-private divide. A strategy of splitting her professional life as a teacher from her personal life as Jessica defines her response to such positioning, and while heterosexual teachers may also engage such coping strategies, for an LGBT teacher the intensity of this requirement and the possible consequences of failure make these dramatically different experiences. Jessica retains a sense of agency when she actively resists and publicly challenges compulsory heterosexuality, and when she silently refuses to accept the status of victim.

By contrast, Andrew, given his masculinity and some skillful footwork, is able to defend the commonplace hierarchy, but the "uncertain pupil" bears the risk. Gender issues arise here as it is debatable whether Andrew would be in a similarly strong position in a primary school, where he might be more vulnerable to questions about men working with young children, and gay men working with children at all. Yet, overarching all of this, the asymmetry of situated sexualities in schooling is revealed by conscious and unconscious decisions to manage identity on the part of LGBT teachers, the range and implications of which would be both unthinkable and unimaginable for heterosexual colleagues (Sparkes, 1994).

The power of the informal resides in the unspoken and unseen expectations of the heterosexual majority to take effective ownership of the discourse around sexualities, positioning, controlling and trapping LGBT 
teachers in terms of their sexual choices. These teachers are viewed (by other teachers and pupils alike) almost exclusively in terms of these choices as remarked upon by a previous interviewee: "it's that you must have this huge sexuality" [Susan] (Nixon and Givens, 2004). The empathy and support of individual staff colleagues is insufficient to challenge the unsubtle operation of informal structural power: this attempts to keep LGBT teachers in a subordinate position (or out of the profession completely), often promoting a reductionist binary division between straight and gay, and disregarding the fluidity of actual, lived experience from Kinsey onwards (Kinsey, Pomeroy \& Martin, 1948; Kinsey, Pomeroy, Martin \& Gebhard, 1953). Indeed, the hidden curriculum of a heteronormative discourse is reinforced by discussions in staffroom and playground of who "fancies" whom, engagement and wedding rings, sympathetic support for friends/colleagues going through "relationship troubles" and so on. As Atkinson (2005: 90) observes "the normal everyday practices of education" reinforce binaries. Shabi (2005: 35) questions the assumption that, "There is a perception that gay people in Britain are now more visible, more socially acceptable and better protected by the law", suggesting that by contrast, there is no evidence that these messages have been received at a school level.

\section{Further constituents of the matrix}

because of the society I work in as well, because of the community, there's quite a large Muslim population, again that might be a stereotype, but I really don't know how they would accept it. I wouldn't broach the subject with my children without chatting to my headteacher quite a lot about it, but um, I suppose because I'm in primary school as well, it's not really covered...there's no reason for it to come up really, and my school doesn't even do sex education until year 6 , and that is a real watered down version of it because of the community, they almost wimp out of it a bit I think, whereas lots of other schools now are doing it in year 5 or even year 4 , because it's necessary at a younger age, whereas we do the very basic, basic sex education. [Nikki] 
Embedded within networks of power, particularly informal power, other constituents may take a significant part in what constitutes discourses about sexualities in education. The concept of subordination along various different axes highlights the complex constellations of influence which operate in schools (Youdell, 2003). The "race" / religion / ethnicity axis (strictly speaking three axes, but here undifferentiated by the interviewee) functions in reference to disclosing sexualities. Nikki speaks of her conscious decision to delay telling female Muslim teachers about her sexuality, although she recognizes at the same time that she is making the kind of unwarranted assumptions that she would wish others not to make about her, and to which she has already alluded in rejecting a conflation of homosexuality and pedophilia. In terms of sex education at Nikki's school, the implication here is that a significant section of the local population would resist an earlier introduction of this topic, and specific teaching about homosexuality. The school's inclusion policy (following that of the Borough) by which Nikki benefits in terms of employment and sexualities, seems less able to engage the tension of race/religion/ethnicity and sexualities. In personal terms, Nikki believes that a further degree of negotiation is required, and in curricular terms, the school appears to have taken a course of least resistance, to the potential detriment of pupils' knowledge of sex and sexualities. There are similar unresolved questions around gender and race, evidenced by Nikki's remark: "the Somalian children seem to have a big issue with women, respect wise".

Another axis of subordination exists at the intersection of sexualities with the variables of space or geography. Gay space is often associated with gyms, parks, bathhouses and so on especially in its masculine form as space for promiscuity; more critically as that which has to be left behind as a teacher in order to conform with heterosexual norms (Rofes, 2000). By contrast, Nikki seeks a locus for honesty, professional acceptance and domestic respectability. 
I wouldn't feel as if I was being true to myself if I was trying to hide that, so that for me, if I was in a place where I couldn't be open, that would be the wrong place for me. ... we've got our house, we've got our car, and we're doing grown-up things and looking after ourselves really.

It is the dimension of respectability which so discomforted the New Right education agenda of the 1980's, especially in the much reviled fictional account Jenny lives with Eric and Martin (Bösche,1983) and which the promoters of Section 28 were so keen to proscribe ${ }^{2}$ in the phrase: "the acceptability of homosexuality as a pretended family relationship" (DES, 1988). While it might be said that Nikki and her partner have simply submitted to the strong current of heteronormativity, within this particular educational setting and in the light of pervasive heterosexism in schools, an alternative interpretation for their "grown-up things" would be that they are a real family, creating a space for resistance to discriminatory processes. Section 28 attempted to reinscribe discourses around sexualities in schools, thereby in the Foucauldian model denying "the space of freedom ... to analyze, contest and change practices that are being used to construct ourselves and the world" (St. Pierre, 2000). So couples like Nikki’s force power relations to re-form themselves in turn - "power relations are obliged to change themselves with the resistance" (Foucault, 1997: 167) - and Section 28 is removed fifteen years after its creation. However at the micro level of a particular school, we see that the three-fold intersection of community geography, "race"/religion/ethnicity, and sexuality has for the moment all but closed down these resistant spaces in respect of sex education.

In conceptualizing "space for resistance" which may be possible across a range of real-time locations, we realize that power relations subsist differently in different school spaces. The negotiation, even competition, for space is exemplified in Laura's description of a homophobic incident: 
I had a situation where some quite rough boys, quite aggressive boys - whilst I was teaching a lesson - came onto the tennis courts on their bikes and rode straight through the tennis courts and were shouting homophobic abuse at me. I then removed the children from the situation, and we had to walk down a small little alley of the school, and they all stood around me and were shouting things ...

Outside sports areas and a small alley seem in this account to be beyond the reach of official school policy, where a group of boys (outsiders?) are able to take physical possession of space and impose their own alternative world-view, in a scenario reminiscent of Golding's Lord of the Flies (1954). The descriptions and analysis earlier in this article also suggest that spaces like classrooms and staffrooms remain contested loci of sexualities equality, notwithstanding policy changes.

\section{Conclusions}

Interviews with three serving LGBT teachers as part of a longitudinal project have provided the basis for an exploration of the life experiences (both personal and professional) of LGBT teachers within the legislative "life and death" of the discriminatory legislation Section 28. We have engaged the exciting deconstructive work envisaged by critics like Davies (1997) as a key part of poststructuralist methodology to discover a complex set of answers to questions of policy, practice and theorization around sexualities in schools. Our conclusions are these: firstly, that concerning sexualities in schools, the general picture is complex, multilayered, shifting and open to different interpretations; however, the official policy climate is markedly different after Section 28, both at a UK national government level and in the way school policy interprets and encourages new thinking, at least in the interviews analyzed here. The detailed operation of such policies and the question of responsibility for implementation remain doubtful however. There remains the risk that LGBT teachers are seen as responsible for "their" issue. 
Secondly, we draw conclusions about this complexity: the discourse about sexualities in the schools' community is played out within a matrix of spaces, relationships and constituent variables which describe, inform, and control that discourse. Macro spaces include the school itself, the domestic setting of teachers' private lives and the half-way house of social-leisure places where teachers go together; within this, there are micro spaces of classroom, staffroom and playground. Relationships include those between staff (including managerial interactions), between staff and pupils, between staff and parents, between staff and governors, between pupils, between schools and their local communities, and so on. More abstract variables concern gender, "race", religion, ethnicity, age and socio-economic class. There is a play, therefore, between other discourses and the sexualities' discourse in which each appears to struggle for dominance via the interpretation of particular school communities. Schools are shot through with such disciplinary structures around sexualities (Foucault, 1998), but their effects are differential depending on status (teacher or pupil), gender and sexual preference. The experiences of these three teachers highlight these underlying complexities. As student teachers under the shadow of Section 28 they regretted the curricular silence about sexualities in their pre-service courses, but looked forward to being 'Out' as teachers. As teachers freed from Section 28, in law at least, identity management has been a more complex issue for them than they had anticipated, but they nevertheless perceive themselves as professionally established, perceptions reinforced by promotions within their first teaching posts.

A third area of conclusion seeks to answer questions about the extent to which official policy is affecting "deep" change in schools. According to the evidence of these interviews, the discourse of sexualities inscribed within this matrix has so far been little altered or advanced by the changing tone of official pronouncements; or following a more postmodern analysis, discourses which work against a more emancipatory approach to 
sexualities in schooling continue to be broadly hegemonic. There is, therefore, evidence of continued discrimination (homophobia and heterosexism) at individual and institutional/structural levels. This results in necessary management strategies being employed by teachers to avoid being trapped by others' constructions of their sexual identity, and to retain some small measure of agency. Pupils are also affected by this continuing hegemony, as for example in one school, only a diluted sex education program was recommended. For both pupils and teachers, the "pretended family relationship" of Section 28 remains just that: alternative models of the family are still subject to an official imprimatur of silence. It may be that the very density of these constructions militates against change. Fullan (1999) cautions us against expecting too much too soon, for if change in educational settings is highly complex, then reform in equity issues may be even more problematic when they are not in the short-term interest of those in privileged positions. Oakes, Welner, Yonezawn \& Allen (1998: 953) provide theoretical and empirical evidence to back up this claim: "We find that when reforms seek to achieve parity in opportunity and achievement across diverse groups of students, reformers faced enormous challenges." Indeed the evidence here of the personal support and institutional empathy which accompany many of the more depressing stories stands out against attitudes so deeply ingrained that small-scale acts against inequality are easily subsumed.

This implies that recommendations for change are more profound and perhaps more problematic than formerly envisaged. Markowitz, (2005: 40) summarizes this as, "the desire to shift the social construction of knowledge", while Carr \& Kemiss (1986: 91) assert that "practices are changed by changing the ways in which they are understood." In other words, change has to invest our way of thinking, of how we construct knowledge, how we structure our intellectual processes; without this, other changes are but superficial tinkerings. This shift also recognizes that the control of others' reality and perception lies at the heart of inequality and oppression. It resists the temptation to replace one hierarchy with another (Lather, 1991; 1995); 
in other words, pursuing the post-structural re-imagining of different outcomes, and avoiding the danger of imposing new hegemonies.

More concretely, there is something to be gained from the model of race equality (Home Office 2000) and disability equality (Home Office 2005) legislation, if the duties of positive action contained in these two Acts can be applied to sexualities. Nevertheless, a much more radical, cultural vision will be needed if the causes of homophobia and heterosexism are to be tackled in schooling: Stand up for us. Challenging homophobia in schools (DFES / DoH 2004), the official guidance published since our follow-up interviews took place, may come to signify a step in this direction. . Following Fullan (1999: 23), we recognize the strength of collaborative diversity, "working through the discomfort of each other's presence, learning from dissonance, and forging new more complex agreements and capabilities", for the benefit of all. So further enquiry with serving and trainee teachers to establish more evidence about the construction and workings of such matrices described will enable more focused responses to continue what official policy has only just begun. In literal, legislative terms, we joyfully sculpt an Epitaph to Section 28; in cultural, metaphorical, poststructural terms, that sculpture is still a work in progress. 


\section{Acknowledgments}

The authors would like to thank the participants for their generosity, enthusiasm and courage in making this research possible. We would also like to thank the anonymous reviewers; in responding to their observations, we have a learned a great deal. 


\section{References}

Allen, L. (2006) Trying not to think 'straight': conducting focus groups with lesbian and gay youth, International Journal of Qualitative Studies in Education, 19 (2), 163-176.

Atkinson, E. (2002a) The responsible anarchist: Postmodernism and social change, British Journal of Sociology of Education, 23(1), 73-87.

Atkinson, E. (2002b) Education for diversity in a multisexual society, Sex Education, 2 (2), 119 - 132.

Atkinson, E. (2005) Equality, diversity and othering: what happens to identity in a globalised world? in: Satterthwaite, J. \& Atkinson, E. (Eds.) Discourses of Education in the Age of New Imperialism (Stoke on Trent, Trentham Books), 79-84.

Bösche, S. (1983) Jenny lives with Eric and Martin (London: The Gay Men’s Press).

Burridge, J. (2004) 'I am not Homophobic But . . ': Disclaiming in Discourse Resisting Repeal of Section 28, Sexualities, 7(3), 327-344.

Butler, J. (1997) The psychic life of power: Theories in subjection (Stanford, CA; Stanford University Press).

Capper, C.A. (1999) (Homo)sexualities, organisations, and administration: possibilities for in(queer)y, Educational Researcher 28 (5), 4-11. 
Carr. W, \& Kemiss, S. (1986) Becoming critical. Education, knowledge and action research (Lewes, Flamer)

Clarke, G. (1996) Conforming and contesting with (a) difference: how lesbian students and teachers manage their identities, International Studies in Sociology of Education, 6(2) 191-209.

Clarke, G. (2002) Outlaws in sport and education? Exploring the sporting and education experiences of lesbian Physical Education teachers, in: S. Scratton \& A. Flintoff(Eds) Gender \& sport: a reader (London, Routledge), 209-221.

Colvin, M. \& Hawksley, J. (1989) Section 28: A Practical Guide to the Law and its Implications (London: Liberty).

Davies, B. (1997) Constructing and deconstructing masculinities through critical literacy, Gender and Education, 9 (1), 9 - 30.

Department of Education and Science (1988) Local Government Act 1988: Section 28: DES Circular 88/90 (London, DES).

Department for Education and Skills (DFES) (2002) Bullying-don't suffer in silence An anti-bullying pack for schools: DFEE 0064/2000 (London: DFES).

DFES / Department of Health (2004) Stand up for us: challenging homophobia in schools. Available online at http://www.wiredforhealth.gov.uk/PDF/stand_up_for_us_04.pdf (accessed $8^{\text {th }}$ June 2006). 
DFES (2004) Tackling homophobia, Teachers Magazine (Primary) 33, July.

Available online at

http://www.teachernet.gov.uk/teachers/issue33/primary/features/TacklingHomophobia_Primary/ (accessed $8^{\text {th }}$ June 2006).

Department of Trade and Industry (2003) The Employment Equality (Sexual Orientation) Regulations Available online at http://www.dti.gov.uk/employment/discrimination/index.html (accessed $8^{\text {th }}$ June 2006).

Dewar, A. (1993) Will all the generic women in sport please stand up? Challenges facing feminist sport sociology, Quest, (45) 211-229.

Ellis, V. \& Forrest S. (2000) One of them or one of us?, in: M. Cole (Ed.) Education, equality and human rights: 'race', sexuality, special needs and social class (London: RoutledgeFalmer), 78-98.

Ellis, V. \& High, S. (2004) Something more to tell you: gay, lesbian or bisexual young people's experiences of secondary schooling, British Educational Research Journal 30 (2) 213 - 225.

Epstein, D. (Ed.) (1994) Challenging Lesbian and Gay Inequalities in Education (Buckingham, Open University Press).

Epstein, D. (1996) Corrective cultures: Romeo and Juliet, Jane Brown and the media, Curriculum Studies, 4(2), 251-271. 
Epstein, D. (1998) Real boys don't work: 'underachievement', masculinity and the harassment of 'sissies', in:

D. Epstein, J. Elwood, V. Hey \& J. Maw (Eds) Failing boys (Buckingham, Open University Press), 96-108.

Epstein, D. (2000) Sexualities and Education: Catch 28, Sexualities 3(4), 387-394.

Epstein, D., O’Flynn, S., Telford, D. (2003) Silenced sexualities in schools and universities (Stoke on Trent, Trentham Books).

Ferfolja, T. (1998) Australian lesbian teachers - a reflection of homophobic harassment of high school teachers in New South Wales government schools, Gender and Education 10(4), 401-415.

Foucault, M. (1970) The order of things: an archaeology of the human sciences (London, Tavistock Publications).

Foucault, M. (1997) The ethics of concern of the self as a practice of freedom, in P. Rabinow (Ed.) Ethics: Subjectivity and truth (New York, New Press) 281-301.

Foucault, M. (1998) The will to knowledge, the history of sexuality: 1 (London, Penguin).

Francis, B. (2001) Beyond postmodernism: feminist agency in educational research, in: B. Francis \& C.

Skelton (Eds.) Investigating Gender: contemporary perspectives in education (Buckingham, Open University Press). 
Fullan, M. (1999) Change forces: the sequel (London: Falmer).

Gaine, C. (2005) It's OK, we're all white (Stoke on Trent, Trentham Books).

Gee, J. P. (1996) Social linguistics and literacies: ideology in discourses (London, RoutledgeFalmer).

Golding, W. (1954) Lord of the Flies London: Faber.

Griffin, P. (2002) Changing the game: homophobia, sexism and lesbians in sport, in: S. Scratton \& A. Flintoff (Eds.) Gender \& sport: a reader (London, Routledge), 193-208.

Griffiths, M. (1998) Educational research for social justice getting off the fence (Buckingham, Open University Press).

Hawley J. C. (2001) Postcolonial and Queer Theories (London: Greenwood Press).

House of Commons Library (2000) Research Paper 00/47, 6 April 2000, The Local Government Bill [Hl]: The 'Section 28' Debate Bill 87 Of 1999-2000, downloaded from http://www.parliament.uk/commons/lib/research/rp2000/rp00-047.pdf on 8th June 2006.

Home Office (2000) Race Relations Amendment Act, (London: Home Office) 
Home Office (2000) Disability Discrimination Act, (London: Home Office)

Jagose, A. (1996) Queer theory an introduction (New York, New York University Press).

Khayatt, D. (1999) Sex and pedagogy: performing sexualities in the classroom, GLQ: A Journal of Lesbian and Gay Studies, 5, 107-113.

Kinsey, A.C., Pomeroy, W.B. \& Martin, C.E. (1948) Sexual behavior in the human male, (Philadelphia, W.B. Saunders).

Kinsey, A.C., Pomeroy, W.B., Martin, C.E. \& Gebhard, P.H. (1953) Sexual behavior in the human female, (Philadelphia, W.B. Saunders)

Lahelma, E., Palmu, T. \& Gordon, T. (2000) Intersecting Power Relations in Teachers' Experiences of Being Sexualized or Harassed by Students, Sexualities, 3(4), 463-481.

Lather, P. (1991) Getting smart: feminist research and pedagogy with/in the postmodern (New York, Routledge).

Lather, P. (1995) Feminist perspectives on empowering research methodologies, in: J.Holland, M. Blair \& S. Sheldon (Eds.), Debates and issues in feminist research pedagogy (Buckingham, Open University), 292-307. 
Lilley, M. (1985) Gay pupils, Times Educational Supplement, 5(4), 20.

Lincoln, Y. (1993) I and thou: method, voice and roles in research with the silenced, in: D. McLaughlin \& W. Tierney (Eds.) Naming silenced lives: personal narratives and processes of educational change (London, Routledge), 29-50.

Lorde, A. (1984) Sister outsider (Freedom, CA; Crossing Press).

Mac an Ghaill, M. (1994) The making of men (Buckingham, Open University Press).

MacNaughton, G. (2000) Rethinking gender in early childhood education (London, Paul Chapman).

Markowitz, L., (2005) Unmasking moral dichotomies: can feminist pedagogy overcome student resistance? Gender and Education, 17 (1), 39 -55.

Nixon, D. (2003) Voices crying in the wilderness? theological reflections on queer stories from trainee teachers, Theology and Sexuality, 10(1), 93-117.

Nixon, D. \& Givens, N. (2004) “Miss, you're so gay." Queer stories from student teachers, Sex Education, 4 (3), $217-237$. 
Oakes, J., Welner, K. Yonezawn, S. \& Allen, R. (1998) 'Norms and politics of equity-minded change', in: A. Hargreaves, A. Lieberman, M.Fullan \& D.Hopkins (Eds.) International Handbook of Educational Change (Donrecht, Kluwer Academic Publishers), 952-973.

Reay, D. (2001) 'Spice girls', 'Nice Girls, 'Girlies', and 'Tomboys': gender discourses, girls' cultures and femininities in the primary classroom, Gender and Education 13 (2), 153-166

Rhoads, R.A. (1994) Coming out in college (the struggle for a queer identity) (London, Bergin \& Garvey).

Rhoads, R.A. (1997) Crossing sexual orientation borders: collaborative strategies for dealing with issues of positionality and representation, Qualitative Studies in Education, 10 (1), 7-23.

Richardson, L. (1990) Writing strategies: reaching diverse audiences (London, Sage).

Robinson, Kerry H., (2005) Reinforcing hegemonic masculinities through sexual harassment: issues of identity, power and popularity in secondary schools, Gender and Education, 17 (1), 19 -37.

Rofes, E. (2000) Bound and gagged: sexual silences, gender conformity and the gay male teacher, Sexualities 3 (4), 439-462. 
Rogers, M. (1994) Growing up lesbian: the role of the school, in: D. Epstein (Ed.) Challenging lesbian and gay inequalities in education (Buckingham, Open University Press).

Sedgwick, E. K. (2005) Axiomatic, in: I. Morland \& A. Willox (Eds.) Queer Theory (Basingstoke, Palgrave Macmillan), 80-201.

Shabi, R. (2005) "Lessons in Loneliness", The Guardian, October 1, 2005.

Smith, A.M. (1990) A symptomology of an authoritarian discourse: the parliamentary debates on the promotion of homosexuality, New Formations: A Journal of Culture/Theory/Politics, 10, 41 - 45.

Sparkes, A. C. (1994) Self, silence and invisibility as a beginning teacher: a life history of lesbian experience, British Journal of Sociology of Education, 15(1), 93-118.

Spivak, G. C. (1993) Outside in the teaching machine (New York, Routledge)

Squires, S. L. \& Sparkes, A. C. (1996) Circles of silence: sexual identity in physical education and sport, Sport, Education and Society, 1(1), 77-101.

Squirrell, G., (1989) Teachers and issues of sexual orientation, Gender and Education, 1(1), 17-34. 
St. Pierre, E. (2000) Poststructural feminism in education: an overview, International Journal of Qualitative Studies in Education, 13(5), 477-515.

Talburt, S., (2000) On not coming out: or reimagining limits, in: W. Spurlin (Ed.), Lesbian and gay studies and the teaching of English: positions, pedagogies and cultural politics (Illinois, National Council of Teachers of English), 54-78.

Tickle, L. (2000) Teacher Induction: The Way Ahead (Buckingham, Open University Press).

Trenchard, L. \& Warren, H. (1984) Something to tell you (London, London Gay Teenage Group).

Walkerdine, V. (1989) Counting Girls Out (London, Virago)

Walters, S. D. (2005) From Here to Queer: Radical Feminism, Postmodernism, and the Lesbian Menace, in I. Morland \& A. Willox (Eds), Queer Theory (Basingstoke, Palgrave Macmillan), 6-21.

Williamson, I., (2001) Sexuality, in D. Hill \& M. Cole (Eds.), Schooling and equality; fact concept and policy (London, Kogan Page), 202-229. 
Youdell, D. (2003) Identity Traps or How Black Students Fail: the interactions between biographical, subcultural, and learner identities, British Journal of Sociology of Education, 24(1), 3-20.

Youdell, D. (2005) Sex-gender-sexuality: how sex, gender and sexuality constellations are constituted in secondary school, Gender and Education, 17(3), 249-270. 


\section{Footnote text}

\footnotetext{
${ }^{1}$ This article is a revised version of a paper originally presented under the same title at the British Educational Research Association conference in September 2004.

${ }^{2}$ The Minister of Parliament who introduced a clause prohibiting the promotion of homosexuality by local authorities in the Committee Stage of the Local Government Bill1987-88 cited Jenny lives with Eric and Martin to justify his proposal (House of Commons Library 2000: 8). It was subsequently suggested that only one copy of the book had been in circulation at this time, and that the Chief Education Officer of the Inner London Education Authority had ruled that it should not be made available in school libraries (Colvin \& Hawksley 1989).
} 